\title{
Recommendations regarding Cultural Organizations and Institutions
}

The following section reproduces policy recommendations how to combat antisemitism regarding cultural, educational and research institutions and organizations, as well as regarding the internet, its influencers, and its users for the fight against antisemitism. These policies were developed for the Catalogue of Policies to Combat Antisemitism ${ }^{1}$ and grew out of all research presented at the conference "An End to Antisemitism!" in Vienna, February 18-22, 2018. These studies pertain to the emergence and growth of antisemitism within the sectors of culture, education, and academic research. They concern the effects of antisemitism within the mentioned areas and help to develop recommendations for the fight against it.

The contributions in questions can be found in the previous section of this volume. Further articles that contributed to the recommendations presented below are published in volumes 4 and 5 of the conference proceedings An End to Antisemitism!, both forthcoming.

This catalogue is indebted in its understanding of culture to the definition of Clifford Geertz: "man is an animal suspended in webs of significance he himself has spun, I take culture to be those webs." ${ }^{2}$ Culture is thus not restricted to the arts but regards any collection of symbols-be they written, oral, visual or otherwise-that construct meaning. Cultural organizations and institutions are not only museums, exhibition halls, theaters and operas but all other organizations and institutions that participate in the process of constructing cultural meaning ranging from political institutions like the UNESCO to universities, publishing houses, newspapers, radio or TV stations. Much of this process now happens online in social media, chat rooms, blogs and other forms of Internet communication such as Wikipedia. Furthermore, with regard to the humanities, but to a lesser degree also with regard to the social sciences and even the sciences, academic research contributes to the making of cultural meaning, too. Education is obviously another important part of the cultural process. Given the special importance of the Internet, academic research, and education for combating antisem-

1 A. Lange, A. Muzicant, D. Porat, L. H. Schiffman, M. Weitzman, An End to Antisemitism! A Catalogue of Policies to Combat Antisemitism (Brussels: European Jewish Congress, 2018), 51-92. 2 C. Geertz, "Thick Descriptions: Toward an Interpretative Theory of Culture," in The Interpretation of Cultures: Selected Essays, ed. C. Geertz (New York: Basic Books, 1973), 3-30; 5.

Ә OpenAccess. ( ) 2019, Armin Lange, Kerstin Mayerhofer, Dina Porat, Lawrence H. Schiffman, published by De Gruyter. (cc) BY-NC-ND This work is licensed under the Creative Commons Attribution-NonCommercialNoDerivatives 4.0 License https://doi.org/10.1515/9783110618594-028 
itism, we will dedicate special chapters to recommendations for educational and Internet decision makers.

It has to be emphasized that the policy recommendations addressed to cultural decision makers and influencers are based on a field of research that is in its infancy. This is all the more regrettable as the embodiment of antisemitic stereotypes in the cultural and religious memories of the world has a key function in perpetuating negative perceptions of Jews. Since antiquity, antisemites have made every effort to manipulate the cultural memories of the world and continue to do so today. Their goal was and is to embody negative perceptions of Jews and Judaism in the world's cultural memories and to make antisemitism thus a part of the world's heritage. In this way, antisemitism became and remains a part of the cultural and national identity of many cultures, societies and groups.

Further research on the antisemitic manipulations of the world's cultural memories and on how to counter them is urgently needed. Currently not one research institution exists that dedicates its work to this topic! Long-term strategies for the fight against antisemitism which last for generations do not exist. To change cultural memories, such long-term perspectives are indispensable though. The recommendations below are a first step in what the authors of this catalogue regard as a much needed long-term perspective in the fight against antisemitism.

In their fight against antisemitism, cultural decision makers should aim for five goals in particular:

1. Eradicating antisemitism with cultural decision makers and those who participate in the forming and expressing of cultural memories.

2. Ending false reporting about Jews, Judaism and Israel in the media (see also the recommendations for the business world).

3. Fighting and removing antisemitic contents in the world's cultural memories.

4. Creating positive memory spaces about Jews and Judaism in the world's cultural memories and/or emphasizing those positive memory spaces about Jews and Judaism that already exist.

5. Embodying a correct depiction of the history of antisemitism in the cultural memories of the world and making all voices of the victims of antisemitism heard.

To achieve these five aims, as with our recommendations to all other decision makers, we advise a five-step process.

1. Assessment: Assessing the level of antisemitism in a culture or society, as well as inside cultural and academic institutions or organizations, or inside a profession. 
2. Comprehending the problem: Analyzing which parts of a cultural memory create Jew- hatred inside a society and/or culture and how cultural memories have been and are manipulated to incite Jew-hatred, i.e., analyzing what motivates antisemitism in the cultural process as well as the antisemitic attitudes of those who participate in it.

3. Awareness-raising: All members of a society/culture, cultural institutions, organizations, etc. need to be alerted to the antisemitism in their culture/society.

4. Application of policies for combating antisemitism.

5. Adjusting the general policies to combat antisemitism: The general policies suggested below need to be adjusted to the specific needs of each culture, society, cultural institution and organization.

\section{Assessment: Assessing where a Culture or Society as well as a Cultural Institution, Organization, or Profession Stands regarding its Level of Antisemitism}

In the area of culture, the assessment of antisemitism is a dual process that should be guided by the IHRA's Working Definition of Antisemitism. ${ }^{3}$ (1) The level of antisemitism needs to be assessed for a whole culture and/or society. This assessment can be the same as the assessment of the level of antisemitism in a country or a transnational bloc. (2) The level of antisemitism in each cultural organization and institution needs to be assessed as well.

For the assessment of the level of antisemitism, independent scholarly/scientific institutions need to be created in cooperation with Jewish organizations (see recommendations for academic institutions). Their independence will vouch for an uncompromised assessment, and their expertise will insure the highest quality of research. Assessments of the level of antisemitism in a culture or a society as well as inside each cultural institution, organization, or profession should be repeated on a regular basis to allow for an appreciation of how effective the combating of antisemitism was after the application of specific policies. The monitoring of antisemitism has to be public and should always lead to interventions.

3 International Holocaust Remembrance Alliance, Working Definition of Antisemitism, issued May 26, 2016, https://www.holocaustremembrance.com/node/196. 


\section{Comprehending the Problem}

It is not enough to assess the level of antisemitism in a given society or culture by surveys and other means. To identify the causes for such antisemitism requires analyzing which parts of a cultural memory create Jew-hatred inside a society and/or culture and how cultural memories have been and are manipulated to incite Jew-hatred. This analysis is all the more urgent because the cultural study of antisemitism is a field of academic research that is in its infancy. While the history of antisemitism was studied in some areas extensively and less thoroughly in other areas, and while research exists for the antisemitic traditions of some Christian churches, antisemitism in the Islamic world remains under-researched (see recommendations for on religious institutions). Left-wing antisemitism and anti-Zionism remain under-researched as well. An analysis as to how contemporary antisemitism draws on the sources of ancient, medieval, early modern and modern antisemitism is as much needed as an assessment of how the different forms of antisemitism connect and influence each other on a trans-religious and trans-cultural level. Therefore, research institutions should be created and research should be encouraged to identify antisemitic stereotypes and antisemitic traditions in the cultural memories and cultural heritages of the world and to study the mechanisms of Jew-hatred in the cultural process (see recommendations for academic institutions).

\section{Awareness-raising: All Members of a Society/Culture, Cultural Institutions, Organization etc. Need to Be Alerted to the Antisemitism in their Culture/Society}

It is necessary to raise awareness about the indebtedness of many cultures and their cultural memories to antisemitic philosophies. At the same, it is necessary to raise awareness about antisemitism inside cultural organizations and institutions. Accordingly, this awareness-raising must be a two-step process with two different sets of addressees. In practice, both steps will often be intertwined.

1. Raise awareness among cultural decision makers, influencers, and members of cultural organizations and institutions.

2. Raise awareness among all members of a given culture and/or society. 
To raise the awareness for antisemitism with cultural decision makers and influencers as well as with the members of a cultural institution or organization, we recommend that they participate in special training courses and seminars about both the history and culture of antisemitism as well as about the history, culture, and religion of Judaism. In addition, they should be exposed as much as possible to living Judaism both in their home countries and in Israel. Positive practical experiences with Jewish culture and religion are of key importance to sensitize anyone to Jew-hatred. Public pressure can also help to raise the awareness towards the eventual antisemitism inside a given cultural organization and institution.

Cultural decision makers and influencers can help to educate the general public about the level of antisemitism in its culture. Awareness-raising of antisemitic contents in the cultural memories of our world needs to be achieved for each generation anew to immunize it against Jew-hatred. The policies recommended in this chapter are therefore not a one-time endeavor but will have to be repeated for each generation.

\section{Application of Policies for Combating Antisemitism}

For all policies recommended below to cultural decision makers, funding is essential and should not be left to the financial support of NGOs and cultural institutions alone. Each cultural institution should spend 1 percent of its budget to fight antisemitism, and, in addition, a significant part of the overall public budget that is recommended above (see Executive Summary) and below (see recommendations for governments, political organizations, and institutions) should be reserved for the fight against antisemitism in cultural institutions and dispensed to their decisions makers.

Cultural decision makers and influencers should combat antisemitism with both a short-term and long-term perspective. Policies that aim at restraining antisemitism in a cultural institution or organization can be effective in a relatively short time span and should aim at restraining the further spread of antisemitism by cultural decision makers and influencers. Policies which aim at the eradication of antisemitism in the cultural memories of the world can only be effective over the time span of generations and require continued work during that time period. Given the special importance of cultural decision makers and influencers as cultural multipliers and the key function of cultural memories in the spread and perseverance of antisemitism, both sets of policies are at the heart of this catalogue of policies to combat antisemitism. 
Only a combination of five approaches will successfully fight Jew-hatred on a long term-basis:

1. Restrain antisemitism.

2. Disprove the false claims of antisemitic agitation to discredit all past and present written, oral, and visual antisemitic propaganda and remove antisemitic contents from the world's cultural and religious memories.

3. Replace the antisemitic contents of the world's cultural and religious memories with positive memory spaces about Jews and Judaism to achieve a cultural forgetting of Jew-hatred.

4. Assure an accurate depiction of the history of antisemitism and the voice of its victims in the cultural and religious memories of the world.

5. Engage with antisemites on a religious level (see recommendations for religious groups and institutions).

The following policies are therefore recommended.

\subsection{Policies Aiming at the Short-term Restraining of Antisemitism}

Policies that aim at the short-term restraining of antisemitism in cultural organizations and institutions include content related, budgetary, disciplinary, organizational, and educational aspects. The following policies are recommended for cultural institutions and organizations.

- Each cultural organization or institution should endorse and apply the IHRA's Working Definition of Antisemitism (see 565-6).

- Each cultural organization or institution needs to allocate at least 1 percent of its budget to restrain and eradicate antisemitism among its members and in the cultural memories of the world (see below for more details on the latter).

- Depending on the nature and size of a cultural organization or institution, the position of an envoy for combating antisemitism should be created whose work should be supported by a committee in which Jewish organizations are represented should. An example for an organization which should have such an envoy is UNESCO.

- An early warning system needs to be established that is based on the IHRA's Working Definition of Antisemitism. Incidents of antisemitism need to be publicly denounced by the media, cultural decision makers and influencers to create by way of naming and shaming an awareness of all forms of contemporary antisemitism. 
- Antisemitic cultural organizations and institutions need to be dissolved and/ or blacklisted.

- Antisemitic cultural decision makers or influencers as well as antisemitic employees or antisemitic members of cultural organizations and institutions need to be dismissed, suspended from duty, or expelled. This includes the membership in scholarly and scientific organizations but also such positions as university professors, museum directors, or the editor-in-chief of a newspaper or news channel. In case of elected offices, antisemitism should be treated as an attitude that forces a cultural decision maker to resign.

- No funding should be allocated to those cultural institutions that are antisemitic. Privately owned antisemitic institutions should not be allowed to apply for public funds or enjoy tax benefits.

- Any cultural organization, institution or cultural decision maker and influencer who propagates antisemitism should be exposed to legal punishments ranging from fines to prison sentences depending on the severity of the case.

- When antisemitic rumors arise, cultural decision makers and influencers must stand up immediately and denounce them.

- No cultural organization or institution should participate in antisemitic BDS activities or in any other anti-Zionist activity that rejects the self-determination of the Jewish people.

- Cultural organizations and institutions should condemn such anti-Zionist activities as antisemitism.

- The continuing education of cultural decision makers and influencers should include the history, culture and religion of Judaism as well as the history of antisemitism.

- For new employees of a cultural organization or institution, it should be a mandatory requirement for their appointment to have taken classes in history, culture and religion of Judaism as well as the history of antisemitism.

\subsection{Cultural Forgetting of Antisemitic Memory Spaces in the Cultural Memories of the World}

As explained above, the embodiment of antisemitic stereotypes in the world's cultural memories is mainly responsible for the perseverance of antisemitism over millennia. Furthermore, new antisemitisms developed and still develop by adapting antisemitic stereotypes and canards from those cultural memories to the changed circumstances of modern societies. How much medieval agitation against Jews proves to be effective today was demonstrated when on June 23, 2016 Palestinian President Mahmoud Abbas charged Israeli rabbis of having 
called on their government to poison Palestinian water. Abbas' false accusation was clearly inspired by the medieval antisemitic slander of well-poisoning. He was later forced to withdraw the allegation under international pressure.

There are two reasons for the antisemitic immunity towards logical arguments exemplified by Mahmoud Abbas. (1) To disprove all false facts in antisemitic agitations requires detailed arguments. The sheer amount of the lies in antisemitic agitation makes it impossible to study and disprove them all. (2) The irrational fervor of antisemites identifies antisemitism as a (quasi)-religious ideology that immunizes antisemites to rational arguments.

To end the reapplication of earlier antisemitic stereotypes to contemporary Judaism and the development of new forms of antisemitism, a cultural forgetting of the antisemitic memory spaces of the world's cultural memories needs to be achieved. The policies below all aim at the cultural forgetting of antisemitism. - In regular intervals, media outlets and other cultural organizations and institutions should publish and broadcast documentaries educating the general public about the false claims of antisemitic propaganda and slander. $\mathrm{Mu}$ seums and exhibition halls should do the same with exhibitions.

- Pupils and students need to be taught on both the lower and higher levels of education about the false nature of antisemitic agitation.

- Special Webpages should be created and made easily accessible to help prove the claims of antisemitic agitation false.

- Journalists and other cultural influencers need to be supported in their exposure of antisemitic lies quickly in order to stem the dissemination of antisemitic agitation.

- All media outlets that propagate antisemitic stereotypes or antisemitism should be the object of public criticism and boycott. An example of such dissemination is the marketing of antisemitic books authored by Joseph Goebbels on Amazon (see chapters on recommendations regarding the Internet and Business). The same books can be downloaded worldwide free of charge from platforms like archive.org.

- All existing legal means need to be used to respond to antisemitic agitation in the media. If no such legal means exist, the necessary legislation needs to be created.

- Isolated cases of the propagation of antisemitic stereotypes in media outlets should result in a fine.

- Media outlets that propagate antisemitic stereotypes or antisemitism regularly should be closed and prohibited.

- Media outlets that in any way participate in false or biased reporting about Israel should be the object of public criticism. 
- Neither virtual nor real libraries should provide anyone with antisemitic literature, films, music, etc. Only scholarly and national libraries should hold antisemitic items. Access to these antisemitic items should be restricted to researchers who need them for their work in studying and combating antisemitism.

- Publications of central written, oral, and visual parts of a cultural memory should include introductions, marginal notes, subtitles or captions that warn about antisemitic passages and depictions in them (examples include the antisemitic stereotypes in Shakespeare's The Merchant of Venice).

- All antisemitic texts, films, music, blogs, Webpages, and other contents need to be publicly denounced and blacklisted. This includes not only books like Hitler's Mein Kampf, The Protocols of the Elders of Zion, Henry Ford's The International Jew but also texts like John Chrysostom's "Sermons Against the Jews," Chaucer's The Prioress's Tale, Luther's treatise On the Jews and Their Lies, Sayyid Qutb's essay Our Struggle against the Jews, and the Syrian TV series Ash Shatat which claims that Jews practice ritual slaughter of Christians today. Publishing houses, music labels, Internet platforms, etc. should not publish such contents, bookdealers should not sell them, and online repositories should not provide them.

- Antisemitic contents of the cultural memories should only be available in commented editions that identify their lies and explain their dangerous agitation: Such editions are needed by scholars studying antisemitism and by various legal and other institutions that are involved in combating antisemitism. Commercials and advertisements for such editions should only address librarians, experts of antisemitism studies and institutions that are involved in the fight against antisemitism. The commented edition of Hitler's Mein Kampf ${ }^{4}$ is a step in the right direction. That it was and is marketed extensively gives reason to worry though.

- Isolated antisemitic passages in the literature, music and art of the world's cultures should be accompanied with warning annotations and glosses identifying the agitation.

- In any official or unofficial communication, antisemitic vocabulary has to be avoided.

- Buildings, streets, ships, army barracks, universities, etc. should not be named after antisemites. Designations of existing houses, streets, ships, etc. that are named after antisemites need to be changed. Examples include

4 A. Hitler, Mein Kampf: eine kritische Edition, edited by C. Hartmann et al., 2 vols., Munich Berlin: Institut für Zeitgeschichte, 2013-2016. 
the Lagarde-House in Göttingen which still carries the name of this vicious antisemite from the late $19^{\text {th }}$ century. A good practice example is the former Paul-Lagarde-Straße in Munich which since 2016 is called Ilse-Weber-Straße.

- No new memorials should be erected for any antisemites. Existing memorials, such as the one to Karl Lueger in Vienna, need to be demolished.

- Antisemitic artwork at churches and other places need to be removed, such as the so-called "Jew-sow" ("Judensau") at the Church of Wittemberg.

- Antisemitic artwork should not be displayed in museums and exhibitions. Antisemitic music and plays should not be performed in opera houses or theaters.

- The measures regarding antisemitic naming practices, antisemitic artwork, memorials to antisemites, etc. cannot be restricted to modern times but need to include antisemites and antisemitic art from all periods.

- Plaques should explain changed names, removed memorials and removed art.

- In the case of state incitement to antisemitic hatred, such as in the case of Iran, governments should endeavor to stop the dissemination of these messages through internet, satellite TV, and other channels.

- In the case of antisemitic states such as Iran, only governments can stop the hate messages they communicate through the Internet, satellite TV, and other channels.

- State or non-state actors that allow antisemitism to spread in textbooks, mosques, and media of these countries need to be denounced and punished.

\subsection{Replacing Antisemitic Memory Spaces in the World's Cultural and Religious Memories}

Cultural forgetting of antisemitism alone is not sufficient to restrain and in the long-run end it.

To eradicate antisemitic contents from the cultural memories of the world completely will most likely remain a utopian goal that can only be reached by approximation as antisemitic canards and stereotypes are even part of the Christian and Muslim Holy Scriptures. Antisemitic agitation aims at the destruction of Judaism both by depicting it in the most negative way possible in the cultural memories of the world and by way of its physical destruction; the former often leads to attempting the latter. The recent ADL report on global antisemitism 
leaves little doubt ${ }^{5}$ that antisemitic agitation has been successful in many parts of the world and with large percentages of the world's population at least with regard to the destruction of a positive cultural image of Judaism.

The cultural forgetting of Jew-hatred needs to be complemented with the embedding or reinforcing of positive images of Judaism in the cultural and religious memories of the world. All cultural organizations and institutions should work to expose humanity to the rich and fascinating universe of Jewish culture in general, and Israeli culture in particular, as hatred cannot be sustained for that which is appreciated.

- Highlighting positive memory spaces about Jews and Judaism by

- Featuring exhibitions about Jewish art (such as the paintings of Marc Chagall).

- Performing Jewish music in opera houses and other venues.

- Playing Jewish plays or positive plays about Judaism in theaters.

- Writing and publishing textbooks and popular books about Jewish history, culture and religion.

- These textbooks and popular books should also explain the significance of Jewish rites (such as circumcision and ritual slaughter) and holy days.

- Producing documentaries for TV channels and radio stations about the same topics.

- Writing daily and weekly journals about these topics as well.

- Making movies about Judaism and the Jewish experience.

- Organizing exhibitions about Jewish subject matter as part of the program of every museum. Judaism should not be a topic for Jewish museums only.

- Emphasizing positive portrayals of Israel. Given that anti-Zionism is one of the most predominant forms of contemporary antisemitism, books, documentaries and movies about the State of Israel are particularly important in the fight against the Israelization of antisemitism and against the anti-Israel political and cultural narratives.

- Israel should be praised as the only country that achieved a working multi-cultural society in the Near East.

- $\quad$ Even during wartime, Israel did not suspend its democratic laws.

5 Anti-Defamation League, “ADL Global 100: An Index of Anti-Semitism,” http://global100.adl. org/. 
- Arab Israeli citizens play a prominent role in the country's institutions, including lawmakers, Supreme Court judges, high-ranking officers in the army, players on the national football team, etc.

- In spite of existential threats to Israel, democratic values stand firm in Israel.

- Making available all the above information not only in English, French and German but also in as many languages as possible (including Arabic, Farsi, Spanish and Russian) and easily available in all these languages both in print and online (open access). It is often very easy to find antisemitic agitation on the Internet but much more difficult to find accurate information about Judaism, the Jewish experience and the State of Israel (see recommendations regarding the Internet).

- Organizing by cultural organizations and institutions cultural exchanges and partner programs as well as joint cultural programs with Jewish communities and Israeli cultural organizations and institutions.

- Establishing programs for multi-cultural dialogue between Jewish and nonJewish groups in the framework of cultural organizations and institutions.

- Creating formal partnerships between cultural organizations and institutions and Israeli and other Jewish organizations and institutions. An English, French, or German TV channel could, for example, cooperate with an Israeli one by broadcasting an Israeli TV program.

- Offering tours to Israel on the broadest possible scale, especially to youth groups but also as part of senior education programs (see recommendations regarding education).

- Translating and publishing Jewish literature and all other forms of Jewish and Israeli cultural expression. The German translations of the crime novels by Batya Gur did much to communicate an accurate image of the State of Israel to the German cultural memory.

- Highlighting Jewish achievements for a given society or country. For this purpose,

- Memorials should be created to celebrate Jewish contributions to the world's heritage.

- Streets, places, parks, houses, universities, schools, etc. should be named after Jewish persons of achievement.

- Memorials should be erected for Jewish persons of achievement.

- Highlighting times of peaceful coexistence between Jews and non-Jews in the cultural memories of the world. Examples include the Constitution of Medina in the Quran, the Golden Age of Jews in Spain during the early period of Muslim rule, or the Golden Age of Jews in the Carolingian Empire. 
- Creating out new cultural organizations and institutions out of the public budget (see recommendations for governments, political organizations, and institutions), dedicated to the education and enlightenment of the general public about Judaism and the fight against antisemitism.

\subsection{The History of Antisemitism in the Cultural Memories of the World}

Positive cultural images of Judaism need to be accompanied in the world's cultural memories by the memory of the horrible consequences of antisemitic agitation and an appropriate depiction of antisemitism as well. The history of antisemitism and of antisemitic persecution cannot be restricted to the Nazis and the Shoah. Antisemitism neither began with the Nazis nor ended with them. While being the greatest catastrophe in human history, the Shoah marks only the peak of a long history of antisemitic persecution that has not come to its end even today. All victims of antisemitism need to be remembered, and a critical memory of all forms of antisemitism needs to be incorporated into the world's cultural memories. If the memory of antisemitic persecution is restricted to the Shoah, all other forms of antisemitism can be ignored more easily and Jew-hatred becomes more acceptable. The problem is illustrated by the verdict of the lawsuit against Jutta Ditfurth. On April $16^{\text {th }} 2014$, Ditfurth called the journalist Jürgen Elsässer a "glowing antisemite." ${ }^{6}$ In a lawsuit at the Munich law court, Ditfurth was forbidden by judge Petra Grönke-Müller to use this description. While the court was in session, Grönke-Müller argued for her decision by claiming that in Germany antisemitism would be an ideology that could not be disconnected from the Nazi period. ${ }^{7}$

To achieve a proper depiction of antisemitism in the world's cultural memories, the following policies are recommended.

- Textbooks, popular books, documentaries, and exhibitions should cover the whole history of antisemitism. A positive example is the BBC documentary

6 E. Wittich, "Manischer Montag: Mahnwachen ziehen Antisemiten an," Jüdische Allgemeine, June 26, 2014, 3. The German original of the quote is "glühender Antisemit."

7 "Ein glühender Antisemit in Deutschland ist jemand, der mit Überzeugung sich antisemitisch äußert, mit einer Überzeugung, die das III. Reich nicht verurteilt und ist nicht losgelöst von 1933-45 zu betrachten vor dem Hintergrund der Geschichte.” "Elsässer gegen Ditfurth,” haGalil.com, October 10, 2014, http://www.hagalil.com/2014/10/ditfurth-3/. ["In Germany, a glowing antisemite is someone who confidently makes antisemitic statements, statements that do not condemn the III ${ }^{\text {rd }}$ Reich and who can thus not be regarded without the historical background of $1933-45 . ”]$ 
"The Longest Hatred" and the book of the same title by Robert Wistrich. ${ }^{8}$ They should be available not only in English, French and German but should be translated into as many languages as possible (including Arabic, Farsi, Spanish and Russian) and easily available in all these languages both in print and online (open access).

- A special topic of such books and documentaries should be the Israelization of the antisemitic heritage, i.e., to raise awareness that classical antisemitic stereotypes are now applied to the State of Israel and its citizens.

- Holocaust museums are important but they need to be complemented by museums that inform and educate about the whole history of antisemitism and antisemitic persecution.

- Other museums and exhibition halls should dedicate exhibitions to the history of antisemitism and antisemitic persecution as well.

- Museums, exhibitions, documentaries, etc. dedicated to the history of antisemitism and antisemitic persecution should aim to reach people through emotional experiences that might help to counter the irrationality of Jew-hatred. Whoever is touched by the suffering of a fellow human being will have great difficulty hating him.

- Memorials and museums should proactively try to reach younger people to engage them in dialogues and discussions in order to change their perspective on antisemitism.

- Next to the Shoah, all other pogroms and persecutions as well as their victims need to be commemorated in their own right. In addition to Shoah memorials, memorials and plaques should be installed for pre- and post-Shoah antisemitic persecutions, such as the pogrom of Granada in 1066, the Farhud in Baghdad (1941), the pogrom of Kielce in 1946, and the attack on the Hypercacher supermarket in Paris on January $9^{\text {th }} 2015$.

- The suffering of the victims of all antisemitic persecutions should be documented and easily accessible online in all relevant languages. Earlier persecutions, such as the Spanish Inquisition, should not be neglected, but present-day victims of terrorist attacks in Israel, victims of Islamic and Christian antisemitism as well as victims of right-wing and left-wing antisemitism, including the BDS movement, are crucial as well. To achieve this goal, the reports of and about such victims should be made available as much as possible online in an open access approach, i.e., free of charge. In addition to their open access availability online, these testimonies should be sold in affordable paperback editions. Print and visual media should provide docu-

8 R. Wistrich, Antisemitism: The Longest Hatred. New York: Pantheon Books, 1991. 
mentaries, movies and articles about them. A good practice example is the work of the USC Shoah Foundation Institute for Visual History and Education (http://sfi.usc.edu/).

\section{Adjusting the General Policies to Combat Antisemitism}

We recommend for each cultural decision maker or influencer to adjust these general policies to the needs of her/his organization or institution.

\section{To Summarize}

Cultural and religious memories play a key role in making antisemitism the "longest hatred." Only the eradication of antisemitic stereotypes from the cultural memories of the world and their neutralization will allow antisemitism to end in a concerted effort over several generations. A combination of five approaches provides a long-term strategy to facilitate that goal: (1) Restraining antisemitism, (2) disproving the false claims of antisemitic agitation to discredit all past and present written, oral, and visual antisemitic propaganda and removing antisemitic contents from the world's cultural and religious memories, (3) replacing the antisemitic contents of the world's cultural and religious memories with positive memory-spaces about Jews and Judaism to achieve a cultural forgetting of Jewhatred, (4) assuring an accurate depiction of the history of antisemitism and the voice of its victims in the cultural and religious memories of the world, (5) engaging with antisemites on a religious level as detailed in the recommendations regarding religious groups, organizations and institutions. 
